
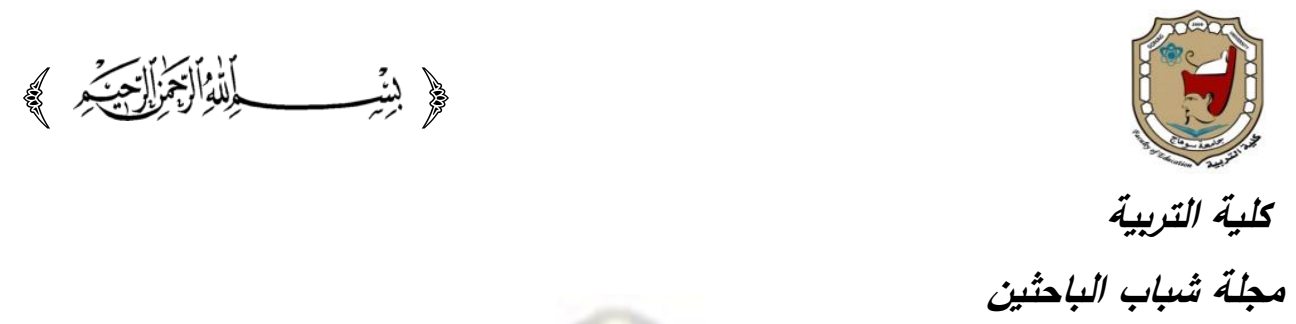

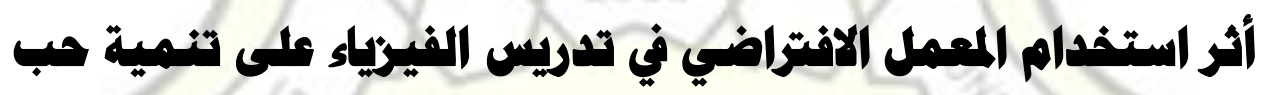
الاستطلاع لدى طلاب الصف الثاني الثانوي الأزهري

( بكثمشتقمنمسالةعلميةتخصص منامجوطرقتديس )

$$
\text { إعداد }
$$

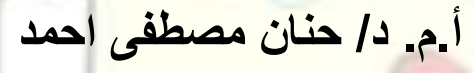

أستاذ المناهج وطرق تدريس

العلوم المساعد

كلية التربية - جامعة سوهاج

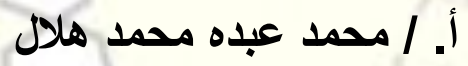

باحث ماجستير - قسم المناهج

وطرق التدريس
أ +د / فايزة مصطفى محمد

أستاذ المناهج وطرق تدريس العلوم المثفرغ

كلية التربية-جامعة سوهاج د /عواطف حسان عبدالحميذ مدرس المناهج وطرق تدريس العلوم

كلية التربية - جامعة سوهاج

\title{
DOI :10.21608/JYSE.2020.
}

مجلة شباب الباحثين في العلوم التربوية العدد الخامس - أكتوبر · F . . م م

Print:(ISSN 2682-2989) Online:(ISSN 2682-2997) 
ملخص

عنوان البحث: أثز استخدام "المعمل الافتراضي" في تدريس الفيزياء على تنمية حب الاستطلاع لاى طلاب الصف الثاني الثانوي الأزهري .

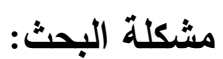

تحددث مشكلة البحث في انخفاض مستوى حب الاسنطلاع لاى طلاب الصف الثاني الثانوي الأزهري، ووجود قصور في المعامل الحالية من حيث إجراء الأنشطة والتجارب المعملية، وحاول البحث الحالي تقصي أثر استخدام المعمل الافتراضي في تدريس الفيزياء على تنمية حب الاستطلاع لاى طلاب الصف الثاني الثانوي الأزهري، وتم استخدام المنهج شبة التجريبي ذو المجموعتين التجريبية والضابطة، والقياس القبلي والبعدي لمتغيرات البحث وتكونت عينة البحث من (9 ؛ ) طالبًا من طلاب الصف الثاني الثانوي الأزهري. مواد وأدوات البحث: برمجية المعمل الافتراضي، دليل الطالب الإششادي، دليل المعلم الإششادي،مقياس حب

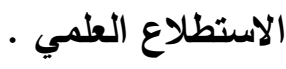
نتائج البحث: - وُجِدَ فرق دال إحصائيًا عند مستوى (ه . . .) بين متوسطي درجات طلاب المجموعة التجريبية (التي درست باستخدام المعمل الافتراضي) ودرجات طلاب المجموعة الضابطة (التي درست بالطريقة المعتادة) في التطبيق البعدي لمقياس حب الاستطلاع لصالح المجموعة التجريبية. 
Summary of the research:

Research Title: The Effect of using the virtual laboratory in Teaching Physics on the development of Curiosity for the Second grade Of Al Azhar secondary students.

Problem of the research : The problem of the research has been fixed In the low level of curiosity for Second grade secondary Al -azhar students, the existing of deficiencies in current laboratories In terms of procedures and laboratory experiments, The current Research tries to Investigate : The Effect of using the virtual laboratory in teaching physics On the development curiosity Second grade secondary Al -azhar students In order to achieve this, the two research groups were chosen, one experimental and one controlling. The semi-experimental approach was used and The experimental and control groups, and the pre- post test measurement of the research variables. The sample consisted of (49) students of second grade secondary Azhari,

Research materials and tools:

virtual laboratory software, guide student guide, teacher guide, scientific curiosity scale.

research results: The search yielded the following results:

- There was a statistically significant difference at $(0.05)$ Between the median scores of the experimental group (studied using the virtual lab)And grades of students in the controlling group (studied in the usual way) In the post-application of the curiosity scale for the experimental group. 
مقدمة:

يعتمد نجاح تدريس العلوم على ما يمتلكه الفرد من مهارات وخبرات عملية وعلمية فيما

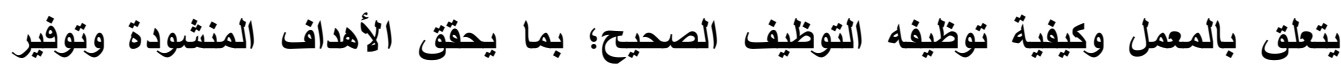

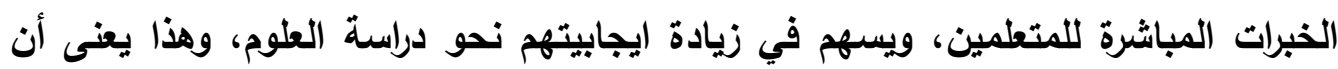
الاهتمام بطرائق تدريس العلوم وتحسينها هو أحد الوسائل الفعّالة لاستمرار النهضة لهضة العلمية والتكنولوجية، ويها يمكن إثارة تفكير المتعلمين وإكسابهم القدرة على حل المشكلات، وتنمية المفاهيم العلمية لايهم، ومن ثََّّ الارتقاء بمستوى اكتسابهم للمعلومات والرغبة في التعلم وحب الاستطلاع العلمي. ويعد المعمل المدرسي من أبرز المجالات التي تساعد في تحويل المجردات إلى محسوسات وترفع مستوى خبرات كل من المعلم والطالب على حد سواء؛ لذا فإن مناهج العلوم الحديثة لا غنى في تدريسها عن المعمل الذي يؤدي استخدامه إلى توفير خبرات حسية متعددة ومتنوعة تعد أساساً لفهم الكثير من المعلومات والتطبيقات العلمية( جميل شاهين،

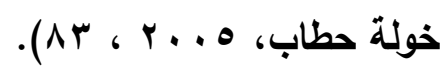

ومع أهمية تدريس العلوم من خلال المعل ودوره المؤثر ، إلا أن هناك عدداً من العوامل التي تعيق استخدامه الاستخدام الأمثل الذي يحقق أهداف تدريس العلوم، والتي تنعكس نتائجها بشكل سلبي على تحصيل المتعلمين، وقدراتهم المهارية، وتفكيرهم العلمي، وقد أثشار

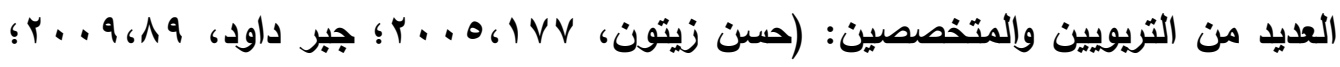

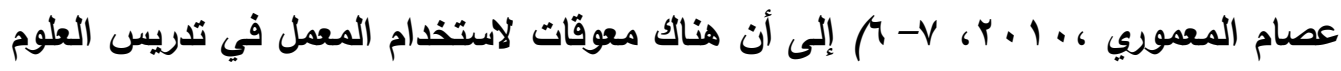

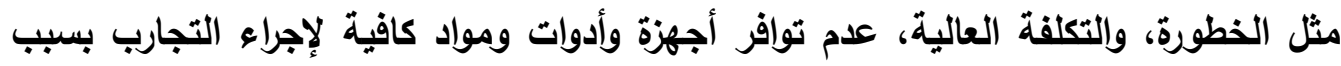
ضيق الوقت، النصاب التدريسي الزائد وكثرة أعباء معلمي العلوم الطبيعية، الكثافة العددية للطلاب في الصف الواحد. ويرى بعض التريويين أن الخبرات التي يكتسبها المتعلم عن طريق مختلف الحواس من خلال تقنيات التعليم كالوسائط المتعددة تكون أسهل وأوضح و أكثر رسوخاً في الذاكرة، وفي لهي بيئة التعلم القائم على الوسائط المتعددة يكون للمتعلم دورٌ فعالٌ في عملية التعلم النشط، ولئ وكما يتحدد دور المعلم في التوجيه الفعال للمتعلمين أثناء سيرهم في عملية التعلم مدفوعين بما لديهم من فضول علمي وحب استطلاع علمي (مجدي إسماعيل،V....؟؛ هالة

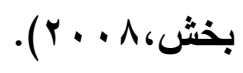


وقد أصبح من الممكن للمتعلم من خلال تقتية المعمل الافتراضي أن يمر بخبرات قـ لا

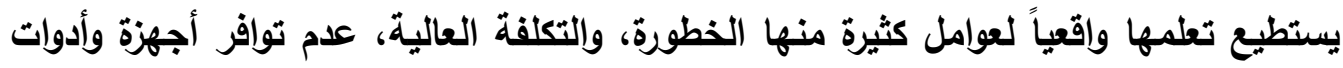
ومواد كافية لإجراء التجارب بسبب ضيق الوقت، الدقة والصغر المتتاهي لحجم العينة المدروسة، كما أن هذه التقنية تقوم على المزج بين الواقع والخيال من خلال خلق بيئة صناعية قادرة على تمثيل الواقع الحقيقي، وتهيئ للفرد القدرة على التفاعل معها، حيث يكون هناك اشتراك لأكثر من حاسة فتجعل المتعامل معها يندمج تماماً وكأنما هو في بيئة الواقع

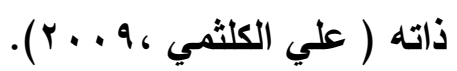

ويحقق المعمل الافتراضي كبديل للمعمل المدرسي في تدريس العلوم فوائدَ عديدةً، حيث إنه يعمل على تقليل المخاطر التي قد يتعرض لها الطلاب نتيجة تنفيذ التجارب مباشرة، ويوفر الوقت والجها عند إجراء التجارب ويقلل التكلفة المادية، ويُمكّن الطالب من تحديد الأخطاء التي يقع فيها وقت المحاكاة، كما أنه يساعد الطلاب في إعادة التجرية عدة مرات وفي أي

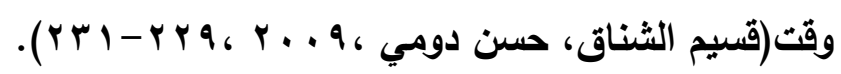

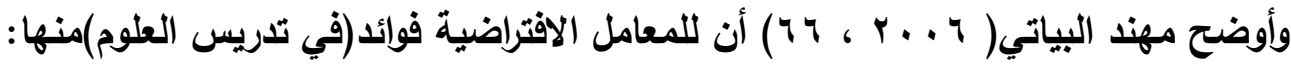
- تعد بليلاً ممتازاً عن المعامل التقليدية بحيث تقدم للطلاب خبرات معرفية ومهارية ووجدانية

- تعطي الطالب قدرة كبيرة على تعلم المفاهيم التي يصعب عليه أن يتعلمها في المختبرات التقليدية.

- تسهم في التظلب على المعوقات التي تحول دون ممارسة التجارب العلمية الواقعية . - توفر للمتعلمين مناخاً علمياً تفاعلياً مشوقاً. - تتيح للطلاب إمكانية ممارسة التجربة العملية خطوة بخطوة. - يمكن بواسطة هذه التقتية الاستغناء عن بعض التجهيزات التي يصعب توفيرها. وقت أُجريت مجموعةٌٌ من البحوث والدراسات هدفت إلى تقصي أثر استخدام المعمل الافتراضي والمحاكاة الاكترونية في تحقيق بعض نواتج التعلم، ومن هذه الدراسات : دراسة كيم تيبارك Kim, H; Tepark, S;\& others,(2001)، غسان

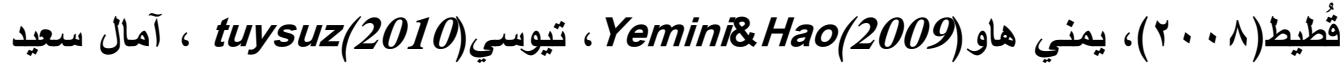

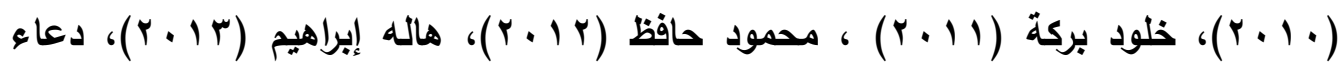




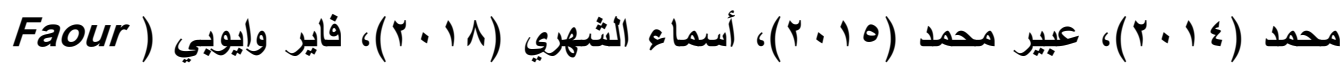
Ayoubi( 2018

ويشغل حب الاستطلاع مكانًا هامًا بين الحاجات النفسية التي يجب أن تثبع عند الفرد حتى يمكن إعداد أجيال تتمتع بعقول خلاقة وقادرة على الابتكار والإبداع والتكيف مع متغيرات

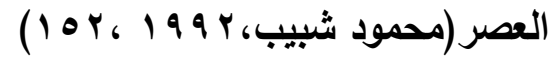
ويعتبر من الدوافع المكتسبة التي تساعد الفرد علي التزود بالمعرفة والقدرة علي التحكم

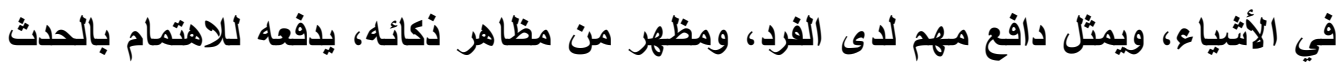

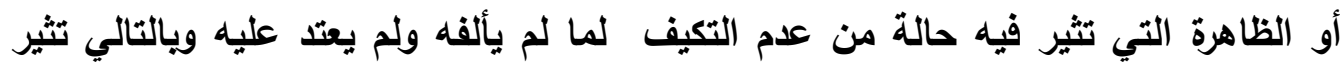
انتباهه نحو الموضوع ، فيبحث لاستكشاف وتقصي المعلومة (شاكر عبدالحميد، عبداللطيف

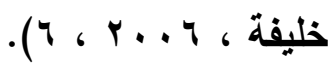

وهو يشكل حجر الزاوية في كثير من مفاهيم التعلم ؛ لأنه ييسر الوظائف العقلية

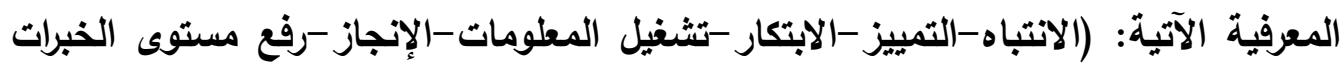
وتذكر الخبرات طويلة المدى-التحصيل الأكاديمي المرتفع-الوصول إلى مستوى مرتفع من الفهر ) ، وكذلك فإن حب الاستطلاع ييسر استخدام الجها العقلي والمعرفي بصفة خاصة ولذلك فإن ضرورة تنميته من العمليات الملحة في هذا العصر بالذات الذي يتسم بالانفجارات

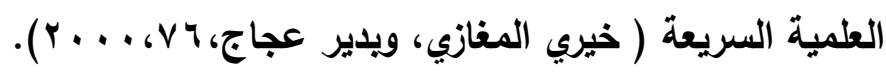
ونظرًا لأنَّ الإنسان محب للاستطلاع بطبيعته، وأن عنصر الجدة والحداثة هام جدًا لإثارة

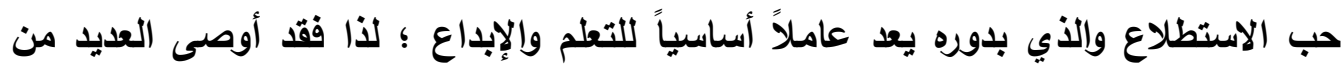
الباحثين باستخدام برامج متنوعة لتنمية حب الاستطلاع مثل: التدريبات الاستكثافية، الأسئلة الحرة غير مقيدة، الأحاث المتناقضة، برامج الكمبيوتر العلمية(رفعت بهجات، ويدير

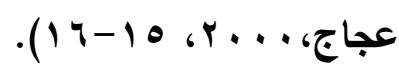
ويمكن التعرف على حب الاستطلاع العلمي، من خلال العناصر السلوكية التي يظهرها المتعلم عندما:

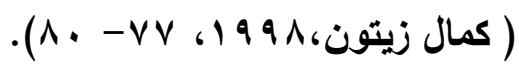
- يتفاعل إيجابيًا نحو عناصر جديدة وغريبة ومتنافرة غامضة فى بيئته وذلك بالتحرك أو الميل نحوها لاستكشافها ومحاولة التعرف عليها. 
- يظهر حاجة أو رغبة لأن يعرف اكثر حول نفسه والبيئة المحيطة به. - يتفصص ما حوله باحثا عن الخبرات الجديدة. - يصر على فحص وتقصى المثيرات البيئية لكى يعرف عنها أكثر ويدرجة أفضل. وهناك عددا من الخصائص التي يظهرها الفرد من السلوك الاستطلاعي، و هي :الجدة

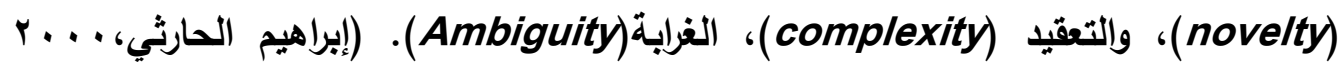

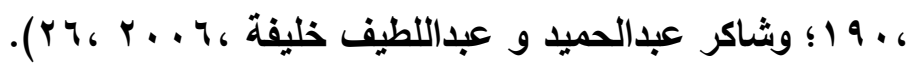

وهناك بعض الفوائد التريوية لتنمية حب الاستطلاع لاى المتعلمين، والمتمثلة في الآتي: - يُعدّ حب الاستطلاع من أهم دوافع البحث والتلفكير والتي تؤدي إلى تقدم العلم والمعرفة. - يعتبر حب الاستطلاع عاملًا مؤثرًا في كثير من جوانب التُعلم الإنساني، والأفراد الذين يتميزون بحب استطلاع عالٍ يكونون ذوي تحصيل أفضل من غيرهم، وتطول فترة فئرة استكشافهم للأحداث والموضوعات، ويستخدمون حواسهر كمصادر متعددة للمعرفة.

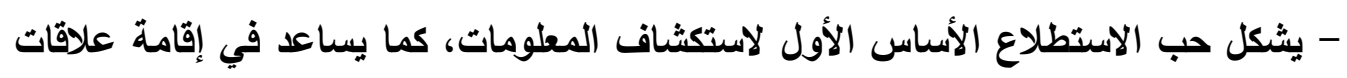

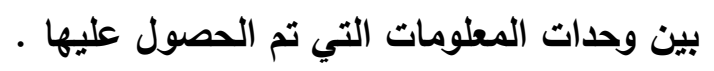

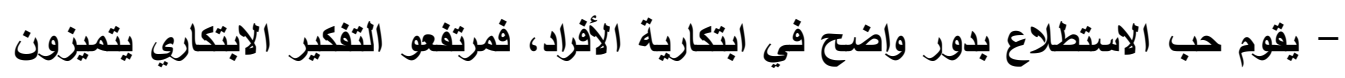

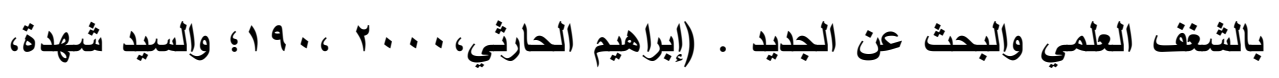

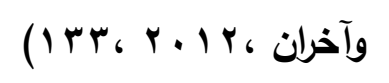

والأفراد مرتفعو حب الاستطلاع غالبا ما يكون تعلمهم للمفاهيم العلمية أفضل من نظرائهم

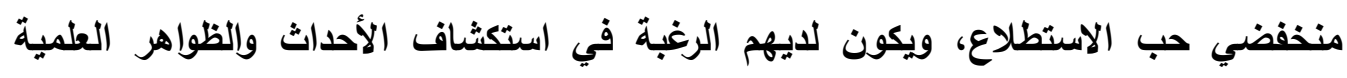

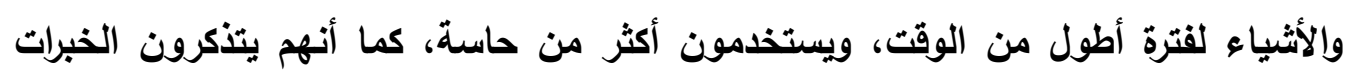

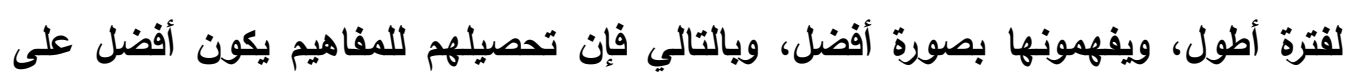
مستويات التذكر والفهم والتطبيق .(Koran, 1980,19)

وقد اهتمت بعض الدراسات بتنمية حب الاستطلاع باستخدام أساليب واستراتيجيات

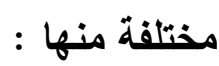




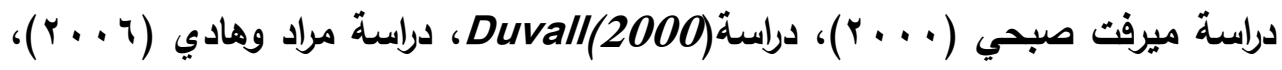

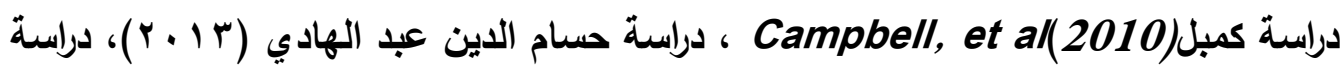

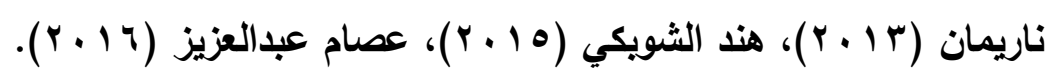

ومن الملاحظ أن هذه الدراسات تناولت تنمية حب الاستطلاع في المرحلتين الابتدائية والإعدادية، وتوجد قلة في الاراسات التي استهدفت تنمية حب الاستطلاع في المرحلة

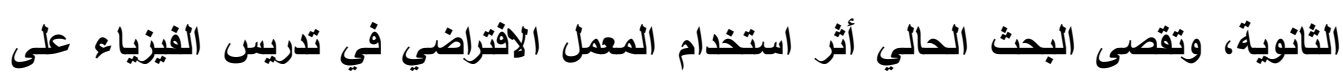
تنمية حب الاستطلاع لاى طلاب الصف الثاني الثانوي الأزهري.

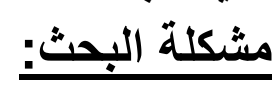
تحددت مشكلة البحث الحالي في: مئيكان انخفاض مستوى حب الاستطلاع لاى طلاب الصف الثاني الثانوي الأزهري، ووجود قصور في المعامل المدرسية من حيث إجراء الأنشطة والتجارب المعملية، وحاول البحث الحالي المئي

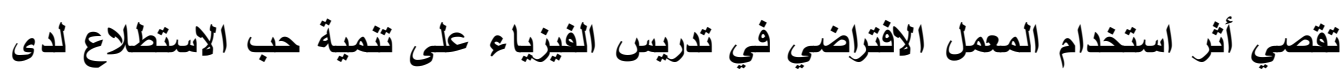
طلاب الصف الثاني الثانوي الأزهري.

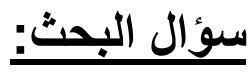
حاول البحث الحالي الإجابة عن السؤال التالي: - ما أثر استخدام المعمل الافتراضي في تدريس الفيزياء على تنمية حب الاستطلاع لدى الإلى

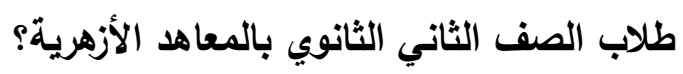

$$
\text { فرض البحث: }
$$

سعى البحث الحالي الى اختبار صحة الفرض الآتي : - لا يوجد فرق دال إحصائيًا عند مستوى (ه . . .) بين متوسطي درجات طلاب المجموعة

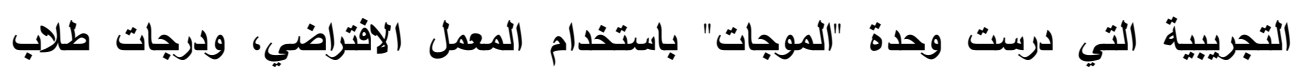

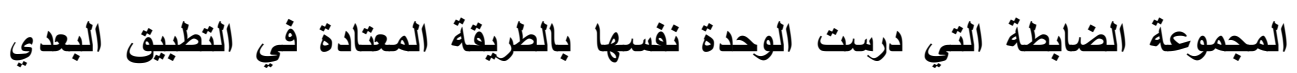
هدف لمفياس البحث: الاستطلاع. - تنمية حب الاستطلاع لاى طلاب الصف الثاني الثانوي الأزهري. 


\section{أثر استخذام المعمل الافتراضى في تدريس.............................. \\ تكمن أهمية البحث: البحث فيما يلي:}

1- قر يسهم هذا البحث في التظلب على الصعويات التي تواجه المتعلمين من خلال استخدام المعمل الافتراضي في تدريس الفيزياء. r - يقدم البحث الحالي مقياسًا لحب الاستطلاع قد يستفيد منها الباحثين في عمل بحوث التريوية أخرى.

r- يوجه نظر واضعي ومطوري ومنفذي مناهج العلوم إلى ضرورة استخدام المعامل الافتراضية في تدريس العلوم بالمراحل التعليمية المختلفة. ع - كما يوجه نظر معلمي العلوم إلى أهمية تنمية حب الاستطلاع من خلال تدريس العلوم لارتباطه بتوجيه نشاط الطالب وجعله مثابرًا مستمتعًا بما يتعلمه.

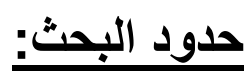
اقتصر البحث الحالي على الحدود الآتية: ا-وحدة "الموجات" في مقرر الفيزياء للصف الثاني الثانوي الفصل الدراسي الأول والمقرة

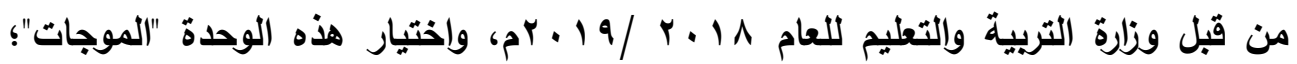
لأنها غنية بالمفاهيم وإلتجارب والاكتثافات والتطبيقات ومناسبتها لمتغير البحث الحالي.

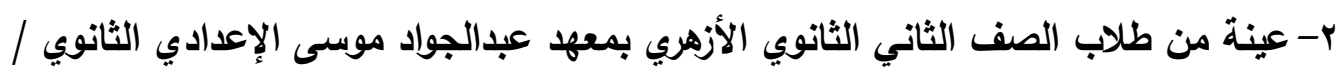

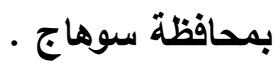

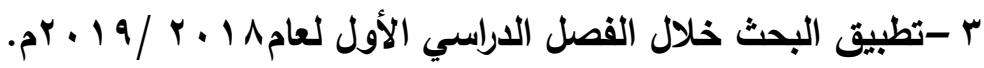
أولاً: مواد الد وأدوات البحث: 1 - برمجية استخدام المعمل الافتراضي في تدريس موضوعات الوحدة المختارة لطلاب الصف

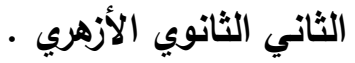
r- دليل إرشادي للطالب يسترشد به أثناء دراسة" وحدة "الموجات " باستخدام المعمل الافتراضي.

r- دليل إرشادي للمعلم في تدريس الوحدة المختارة باستخدام المعمل الافتراضي . 
ثانيًا: أداة البحث: - مقياس حب الاستطلاع العلمي.

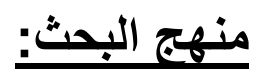
استخدم البحث الحالي : البح

المنهج شبه التجريبي ذو التصميم(Pre- Post-test) الذي يقوم على استخدام مجموعتين إحداهما تجريبية والأخرى ضابطة ، ذات القياس القبلي والبعدي لمتفيرات البحث.

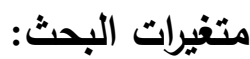
المتغير المستقل: استخدام برمجية المعل الافتراضي في تدريس وحدة "الموجات" للصف

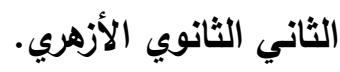
المتغير التابع: حب الاستطلاع. مصطاحات البحث: فيما يلي عرضٌ للتعريفات الإجرائية للمصطلحات المستخدمة في البحث الحالي: المعل الافتراضي: هو عبارة عن معمل الكتروني يحاكى المعمل المدرسي الحقيقي في وظائفه، ومن خلاله يمارس طالب الصف الثاني الثانوي الأنشطة المعملية المتضمنة في وحدة "الموجات" المقررة عليه في مادة الفيزياء. وماه. حب الاستطلاع: الرغبة في استكشاف مواقف جديدة والتعرف عليها من خلال الفضول

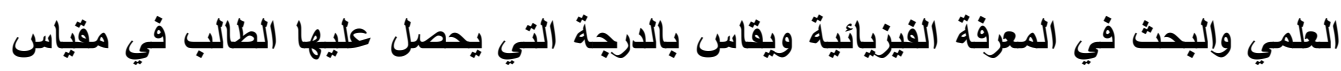

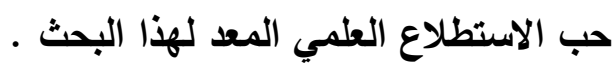

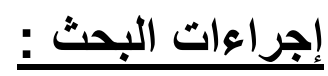
لتحقيق أهداف البحث وللإجابة عن أسئلته واختبار صحة فروضه اتبع الباحث الإجراءات الآتية: ا - الاطلاع على الأدبيات والدراسات العربية والأجنبية التي تناولت متغيرات البحث الحالي r - إعداد إطار نظري في الموضوعات التالية : أ- تكنولوجيا المعامل الافتراضية في تدريس العلوم من حيث: تعريفها- فلسفة المعامل الافتراضية - النظريات التريوية والأصول الفكرية لها- تصنيفاتها-أهميتها - خصائصها - استخداماتها - مميزاتها - معوقات وعيوب استخدامها - مكوناتها - دور معلم 
الفيزياء والتعليم والتعلم بالمعمل الافتراضي- الاراسات السابقة التي تناولت المعامل الافتراضية.

ب- حب الاستطلاع من حيث تعريفة - خصائصه - أهميته و وكيفية تنميته - دور المعمل

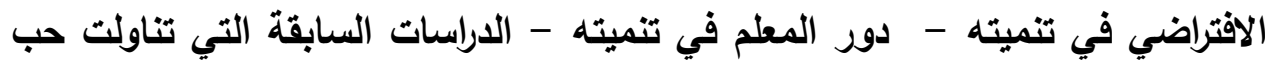

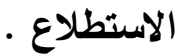

أولاًاجر إعداد مواد البحثى التبعها الباحث لإعداد مواد وادوات البحث:

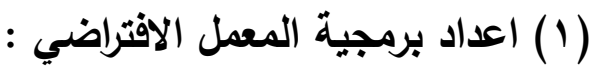

برمجية المعمل الافتراضي عبارة عن برمجية تعليمية تحتوي على دروس وحدة "الموجات" وهي مقسمة الى ثمانية دروس كل درس يحتوي على الأهداف الخاصة بهذا الدرس، والتمهيد، وشرح الدرس بالصوت والصورة والأنثطة والتجارب الموجودة بكل درس، والتثويم الخاص بكل درس للتأكد من مدى فهم الطلاب للارس، وتوجد قائمة في البرمجية تحتوي على المفاهيم الفيزيائية الموجودة في الوحدة. وقد اعتمد الباحث في البحث الحالي على فكرتين رئيستين التطلم بالاكتثاف، والتعلم

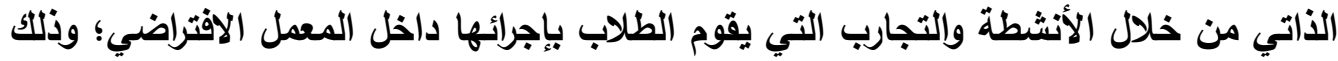
لأنهما يتفقان في جعل عملية التعلم أكثر اثاره وتثويقًا.

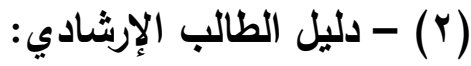
قام الباحث بإعداد دليل إرشادي لطلاب " عينة البحث" ، وتم عرضه على مجموعة من البهن الساده المحكمين المتخصصين في المناهج وطرق تدريس العلوم ، وذلك لإبداء الرأي حول

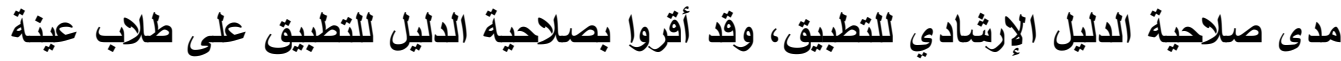

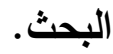

(T) دليل المعلم الإرشادي لاستخدام برمجية المعمل الافتراضي:

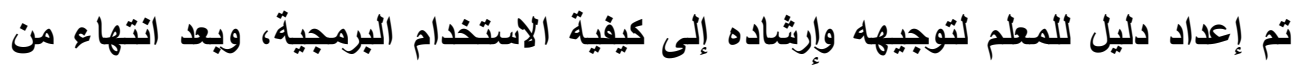

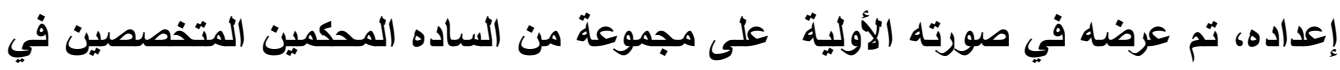
المناهج وطرق تدريس العلوم، وذلك للاستفادة من آرائهم فيما يتعلق بمدى صلاحية العادية الاليل 
الإرشادي للتطبيق، ويعد اجراء التعديلات المطلوية التي أثار اليها الساده المحكمون أصبح دليل المطلم في صورته النهائية الصالحة للتطبيق.

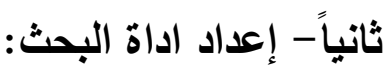
تمثلت اداة البحث في مقياس لحب الاستطلاع، وفيما يلي خطوات إعداده :

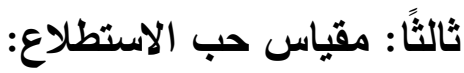
قام الباحث بإعداد مقياس حب الاستطلاع وفقاً للخطوات التالية:

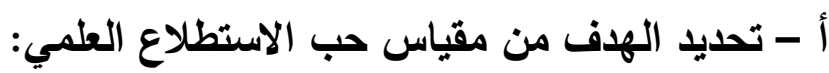
هدف المقياس الى قياس حب الاستطلاع العلمي لاى طلاب الصف الثاني الثانوي الأزهري ، وتقصي أثر استخدام المعمل الافتراضي في تنمية حب الاستطلاع العلمي لايهم . ب - إعداد مقياس حب الاستطلاع العلمي: قام الباحث بإعداد مقياس حب الاستطلاع العلمي وذلك بعد مراجعة بعض الأبطاث التريوية والدراسات السابقة المتعلقة بحب الاستطلاع العلمي، وقد استفاد الباحث من مقاييس

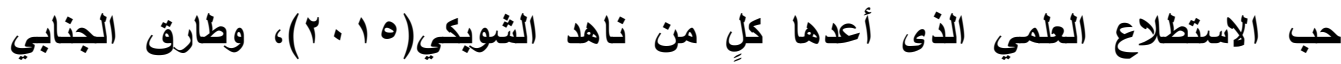

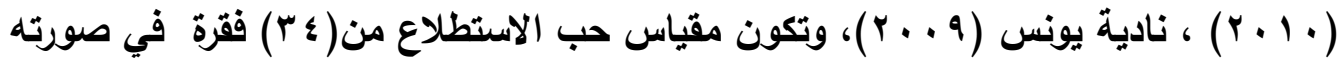
الأولية، وتم استخدام مقياس ثلاثي التدرج ( موافق - غير متأكد - غير موافق)، تأخذ

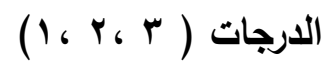

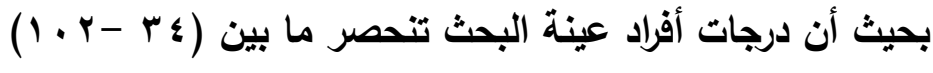

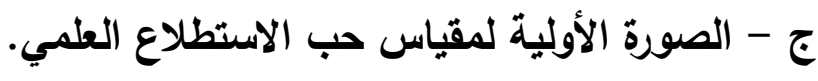
بعد الانتهاء من إعداد المقياس في صورته الأولية، تم عرضه على مجموعة من الساده المحكمين المتخصصين في مناهج وطرق تدريس العلوم بهدف التعرف على آرائهم وملاحظاتهم ، والتأكد من صلاحية المقياس للتطبيق.

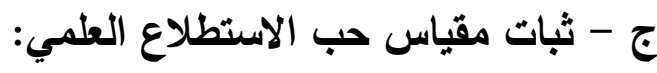
تم حساب ثبات المقياس لكل بعد من أبعاد المقياس، والمقياس ككل وذلكل بعد تطبيقه

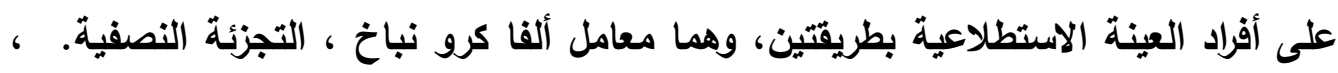

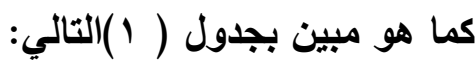


أثر استخدام المعمل الافتراضى في تدريس .

جدول (1 ) معامل الثبات بطريقتي الفا كرونباخ و التجزئة النصفية لكل بعد من أبعاد المقياس المقياس وللمقياس ككل

\begin{tabular}{|c|c|c|}
\hline التجزئة النصفيةة & معامل الفا كرونباخ & ابعاد المقياس \\
\hline .099 & .7 .0 & حب الموضوعات الفيزيائية \\
\hline$\because V O r$ & $.7 \leq 9$ & التمتع بالاطلاع على الموضوعات العلمية. \\
\hline$\because V A 0$ & .979 & حب المشاركتة بالأشطة الصفية \\
\hline .070 &. $.7 \mathrm{~V}$ & حب المشاركتة بالأنشطة اللاصفية \\
\hline$\cdot, \Lambda F$ & .110 & المقياس ككل \\
\hline
\end{tabular}

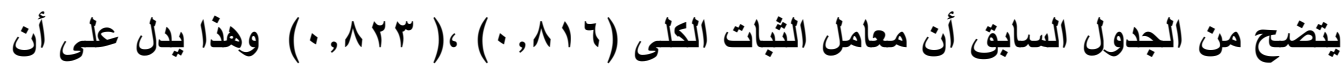

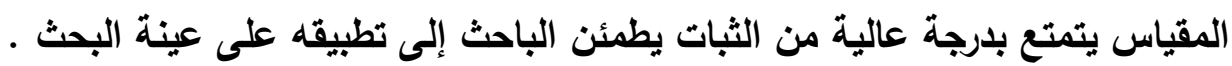
ع - صدق مقياس حب الاستطلاع العلمي: تم حساب صدق المقياس، وذلك للتأكد من صدقة بطريقتين هما الاتساق الداخلي، وصدق المقارنة الطرفية . أ - صدق الاتساق الاخلي : تم التحقق من صدق الاتساق الداخلي بتطبيق المقياس على ماتى عينة استطلاعية مكونة من (Yr) طالبًا، وتم حساب معامل جثمان، وكانت النتائج كما

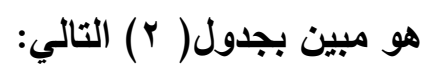
جدول (Y م معامل ارتباط كل بعد من أبعاد المقياس بالأرجة الكلية للمقياس

\begin{tabular}{|c|c|c|c|}
\hline الدلالة الإحصائية & معامل الارتباط & ابعاد المقياس & م \\
\hline \multirow{4}{*}{ دالة إحصائيًا عند } & $\cdot, v \wedge \varepsilon^{* * *}$ & حب الموضوعات الفيزيائية & 1 \\
\hline & $\cdot, \wedge \bullet 7^{* * *}$ & التمتع بالاطلاع على الموضوعات العلمية. & $r$ \\
\hline & $\cdot, \operatorname{vr} \varepsilon^{* * *}$ & حب المشاركة بالأشطة الصفية & $\mu$ \\
\hline & $\cdot, 1 r q^{* * *}$ & حب المشاركة بالأشطة اللاصفية & $\varepsilon$ \\
\hline
\end{tabular}

يتضح من جدول(r) السابق أن جميع أبعاد المقياس ترتبط بالارجة الكلية للمقياس ارتباطًا

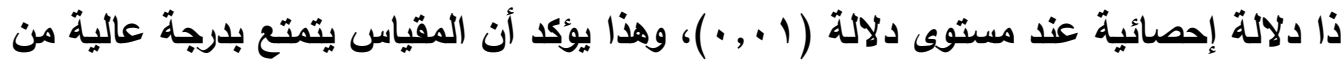
الثبات والاتساق الداخلي. ب - صدق المقارنة الطرفية (الصدق التمييزي) 


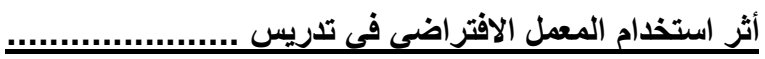

جدول(r) المقارنة الطرفية بين الفئة العليا والفئة الدنيا للمقياس

\begin{tabular}{|c|c|c|c|c|c|c|}
\hline درجة الحرية & قليدة "اتية" & قليمسة "تية" & الأحعياري & الدرجات & العلد & الفئة \\
\hline \multirow{2}{*}{14} & \multirow[b]{2}{*}{$r, 1 \mathrm{qq}$} & \multirow[b]{2}{*}{ r } & $r, V 17$ & $9 r, 10 V$ & $v$ & العليا \\
\hline & & & $\varepsilon, V r$. & $v r, \Delta V 1$ & v & اللنيا \\
\hline
\end{tabular}

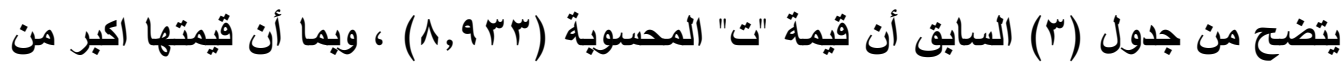

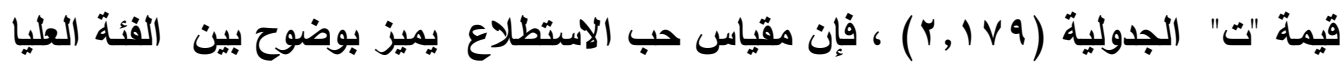
والفئة الدنيا ويالتالي فان المقياس يتمتع بلرجة صدق كبيرة. ه - زمن تطبيق المقياس :

الجدير بالأكر أن الباحث لم يحدد زمناً لتطبيق المقياس فهو ليس اختبارًا لسرعة الأداء.

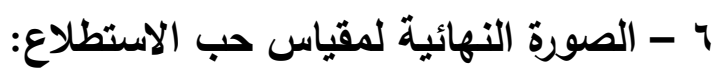
تم ضبط المقياس احصائيًا وأصبح في صورته النهائية ،وصالحًا للتطبيق ويوضح جدول ( ؛ ) التالي مواصفات المقياس.

\begin{tabular}{|c|c|c|}
\hline الوزن النسبي & مجموع العبارات & أبعاد المقياس \\
\hline$\%$ ro & $\Lambda$ & حب الموضوعات الفيزيائية. \\
\hline$\%$ ro & $\Lambda$ & التمتع بالاطلاع على الموضوعات العلمية. \\
\hline$\%$ ro & $\Lambda$ & حب المشاركة بالأنشطة الصفية. \\
\hline$\%$ ro & $\Lambda$ & حب المشاركة بالأثشطة اللاصفية. \\
\hline$\% 1 \ldots$ & rr & المجموع الكلي \\
\hline
\end{tabular}

اجراء وتنفيذ تجربة البحث الأساسية: أولًا: الهرف من تجرية البحث.

هدفت تجرية البحث الحالي إلي تقصي أثر استخدام المعمل الافتراضي في تدريس الفيزياء على تنمية حب الاستطلاع لدي طلاب الصف الثاني الثانوي الأزهري. ثانيًا: التصميم التجريبي للبحث.

تم استخدام التصميم التجريبي الأي يعتمد علي مجموعتين متكافئتين إحداهما تجريبه ، والأخرى ضابطه من طلاب الصف الثاني الثانوي الأزهري للتحقى من هدفي البحث حيث تدريس المجموعة التجريبية وحدة "الموجات "باستخدام برمجية "المعمل الافتراضي" ، بينما

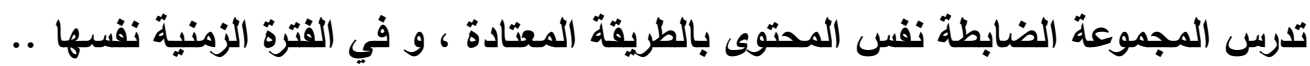


ثالثًا: الإعداد لتجرية البحث

تم إجراء بعض الخطوات لإجراء تجربة البحث، وهي:

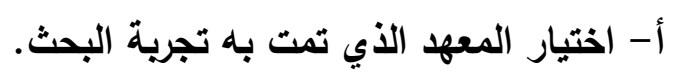

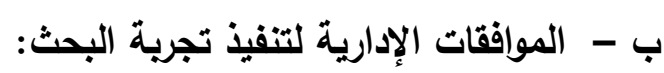

ج - اختيار عينة البحث:

تم اختيار عينة البحث من طلاب الصف الثاني الثانوي الأزهري، وتكونت عينة البحث من

(9 § ) طالبًا من فصلين تم اختيارهما بطريقة عشوائية من بين فصول المعهد.

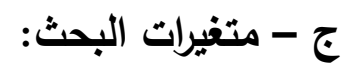

- المتفير التجريبي(المستقل) : استخدام برمجية" المعمل الافتراضي" . r- المتغير التابع : تنمية حب الاستطلاع.

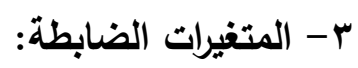

ولضمان تكافؤ مجموعتي البحث تم مراعاة ما يلي: العمر الزمني ، المستوي الاجتماعي والاقتصادي ، القائم بالتدريس، مستوي التحصيل.

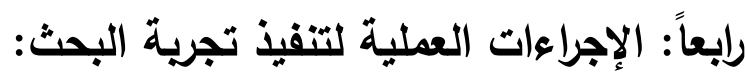
تنقيذ تجربة البحث :

تم تنفيذ تجرية البحث وفقًا للإجراعات التالية : أ - التطبيق القبلي لأداة البحث : تم تطبيق أداة البحث ؛ بهدف التأكد من تكافؤ المجموعتين

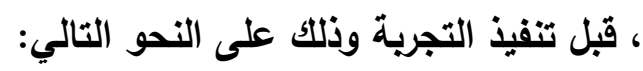
مقياس حب الاستطلاع العلمي. أظهرت النتائج عدم وجود فروق ذات دلالة إحصائية بين مجموعتي البحث، مما يدل علي تكافؤ المجموعتين ، كما هو موضح بجدول (ه ) التالي : 


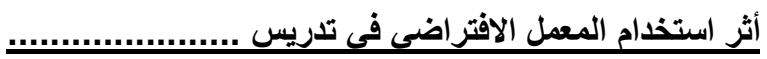

جدول (• ) قيمة "ت" ودلالة الفرق بين متوسطي درجات طلاب المجموعتين التجريبية والضابطة في التطبيق القبلي لمقياس حب التب الاستطلاع العلمي.

\begin{tabular}{|c|c|c|c|c|c|c|c|}
\hline الفصتوى 9 & الجدل 1 " الفصلية & "القصل & الحرجة الفصل 7 & ف المصل ه الانحرا & المتوسط ؛ 1 الفسابي & عدد الطلاب & المجموعة آ \\
\hline \multirow{2}{*}{ إخصائيًا دالة الفصل } & \multirow{2}{*}{ |الفصل 14 ا 14} & \multirow{2}{*}{ 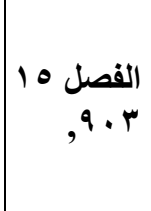 } & \multirow{2}{*}{ |لقصل \& } & 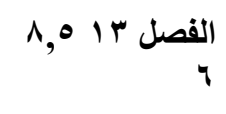 & 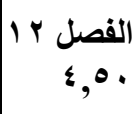 & هر القصل 11 & التجريبية \\
\hline & & & & ع الفصل Yץ •, q & الفصل • r. & الفصل 19 r & الضابطة 11 أف \\
\hline
\end{tabular}

- المدة الزمنية للتجريب :

روعي عامل الزمن عند دراسة الوحدة لمجموعتي البحث ب - تدريس وحدة "الموجات" تم تدريس وحدة "الموجات “باستخدام برمجية "المعمل الافتراضي" لطلاب المجموعة التجريبية.

ج - تدريس وحدة " الموجات" للمجموعة الضابطة باستخدام الطريقة المعتادة في التدريس: د - التطبيق البعدي لأداة البحث : لدرهن هـ - المعالجة الإحصائية: تم استخدام الأساليب الإحصائية المناسبة للاراسات التجريبية التي تعتمد على أسلوب المقارنة بين متوسطات الدراجات التي حصل عليها طلاب المجموعة التجريبية، ومتوسطات الارجات التي حصل عليها طلاب المجموعة الضابطة .

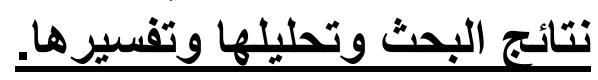
تم تطبيق أداة القياس الخاصة بالبحث الحالي، وهي(مقياس حب الاستطلاع ) تطبيقًا بعديًا، على مجموعتي البحث (التجريبية، الضابطة)، وقد تم رصد الدرجات الخاصة بأداة

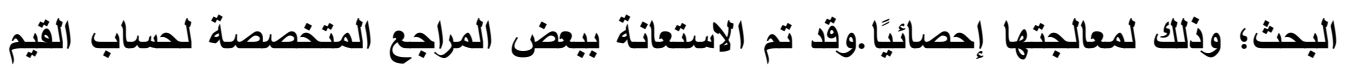

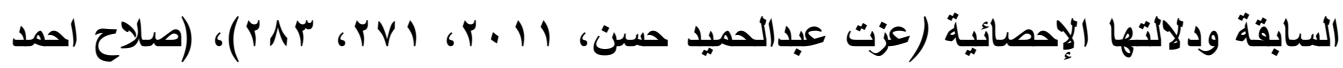

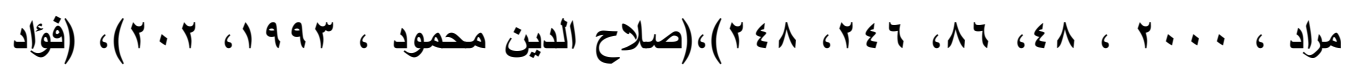

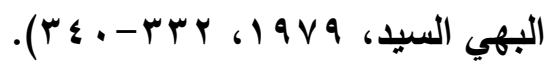
ثانيًا: نتائج البحث وتحليلُها وتفسيرها: للإجابة عن سؤال البحث قام الباحث بما يلي: 
1 - اختبار صحة فرض البحث والأي ينص علي أنه: لا يوجد فرق دال إحصائيًا عند مستوى (ه...) بين متوسطي درجات طلاب المجموعة التجريبية، ودرجات طلاب المجموعة الضابطة في التطبيق البعدي لمقياس حب الاستطلاع لصالح المجموعة التجريبية، ولاختبار صحة هذا الفرض تم حساب المتوسط الحسابي، والانحراف المعياري لارجات مجموعتي البحث في التطبيق البعدي لمقياس حب الاستطلاع، ويوضح جدول (7) التالي هذه النتائج.

جدول (7) قيمة "ت" ودلالة الفرق بين متوسطي درجات طلاب المجموعتين التجريبية

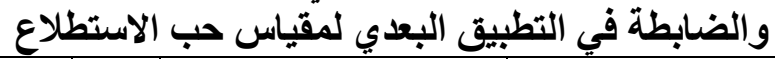

\begin{tabular}{|c|c|c|c|c|c|c|c|c|c|c|}
\hline \multirow{2}{*}{ ه مستولة } & \multirow{2}{*}{ قاتيمة } & \multirow{2}{*}{ "قاتيمة } & \multirow{2}{*}{$\frac{3}{3}$} & \multicolumn{3}{|c|}{ المجموعة التجريبية } & \multicolumn{3}{|c|}{ المجموعة الضابطة } & \multirow{2}{*}{ نتائج تطبيق } \\
\hline & & & & $\varepsilon$ & p & ن & $\varepsilon$ & p & ن & \\
\hline \multirow{5}{*}{ 극 } & r, Tvo & \multirow{5}{*}{$r, \cdot r)$} & \multirow{5}{*}{$\leqslant V$} & $r, Y q$ & $r \cdot T V$ & \multirow{5}{*}{ ro } & זי, r & $1 \wedge, \leqslant \leqslant$ & \multirow{5}{*}{$Y \varepsilon$} & حب الموضويائية \\
\hline & $r,+70$ & & & $r, 14$ & $r, I V$ & & $r, \wedge r$ & 19,04 & & حب اللموضوعاع على العلىية \\
\hline & $r, \leqslant \vee$. & & & $r, r \cdot$ & $r 1,01$ & & $r, \wedge \varepsilon$ & 19,14 & & الأنشبط المشاركة في \\
\hline & $r, \cdot 7 \Lambda$ & & & $r, Y 4$ & $r, \leqslant r$ & & $r, \xi$. & $19, r \varepsilon$ & & حالأنشطة المشاركة فيّة \\
\hline & $\bullet, O V Y$ & & & $\{, 7 \varepsilon$ & $\Lambda V, r r$ & & $\wedge, \vee \wedge$ & Vฯ, rq & & للمقياس ككلية \\
\hline
\end{tabular}

- اجابة سؤال البحث والذي ينص علي : ما أثر استخدام المعمل الافتراضي في تدريس الفيزياء على تنمية حب الاستطلاع لدى لدى طلاب الصف الثاني الثانوي الأزهري؟ d ( للإجابة عن السؤال السابق تم حساب حجم الأثر باستخدام المعادلة (لاستخدام " المعمل الافتراضي " في تنمية حب الاستطلاع لاي طلاب مجموعة

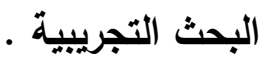




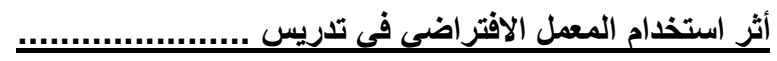

جدول(V حجم تأثير المتغير المستقل (استخدام المعمل الافتراضي) على المتغير التابع(تنمية

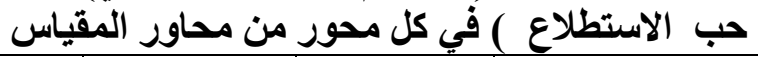

\begin{tabular}{|c|c|c|c|c|}
\hline مستوى الدلالة & حجم التأثير & قيمة & "قايمحسة "تاتة" & المقياس ومحاوره \\
\hline كبير & $\cdot, q 1 v$ & $\cdot, I \vee \varepsilon$ & r, TVO & حب الموضوعات الفيزيائية \\
\hline كبير جدًا & $1, \cdot \varepsilon$ & $\cdot, Y 10$ & $r, 70$ & التمتع بالاطلاع على الموضوعات العلمية \\
\hline كبيز & $\cdot, 9 \wedge \varepsilon$ &., 190 & $r, \leqslant V$. & حب المشاركة في الأنشطة الصفية \\
\hline كبيز & $\cdot, 90 r$ &., $1 \wedge 0$ & $r, \cdot 7 \mu$ & حب المشاركة في الأنثطة اللاصفية \\
\hline كبيز جدًا & $1, \leqslant 94$ & $\cdot, \mu \diamond \Lambda$ & $0,0 V Y$ & الارجة الكلية للمقياس ككل \\
\hline
\end{tabular}

يلاحظ من جدول (V) السابق أن المتغير المستقل (استخدام المعمل الافتراضي) له أثنرّ كبيزٌ على المتفير التابع(تنمية حب الاستطلاع) في الارجة الكلية للمقياس لطلاب مجموعة البحث التجريبية.

- تفسير النتائج المتعلقة بفرض البحث وسؤال البحث: (أظهرت نتائج اختبار صحة الفرض الثاني عن وجود فرق دال إحصائياً عند مستوى ( ه . . . بين متوسطي درجات طلاب مجموعتي البحث في (بعاد مقياس حب الاستطلاع ، وأن

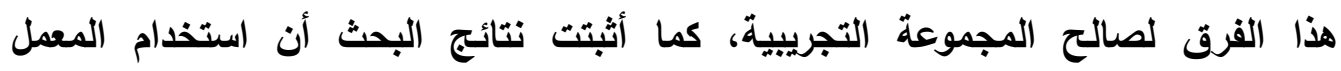
الافتراضي له أثرّ كبيرٌ في تنمية "حب الاستطلاع" لاى طلاب المجموعة التجريبية ، وأن هذا

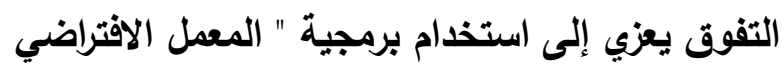
وتتفق هذه النتيجة مع نتائج بعض البحوث والدراسات السابقة التي أكدت على فاعلية استخدام الوسائل التكنولوجية في تدريس العلوم على الطريقة المعتادة ومن هذه الدراسات دراسة ، دراسة كمبل/2010)، et al،Campbel ، ناهد الشويكي (10) (1)، عصام

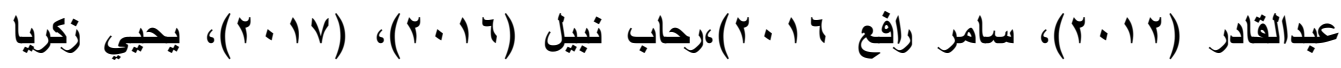
$\cdot(r \cdot 1 \Lambda)$ أ - ثالثًا: التوصيات و البحوثيات المقترة:

في ضوء ما أسفر عنه البحث الحالي من نتائج يوصي الباحث بالآتي: 1 - الاستفادة من تقنية المعامل الافتراضية لتجاوز المشكلات والعوائق التي تواجه المعلم وإلمتعلم في تفعيل الجانب العملي من دراسة علم الفيزياء. 
r - إنشاء موقع للمعامل الافتراضية على الثبكة العالمية لكافة المواد العلمية وللصفوف

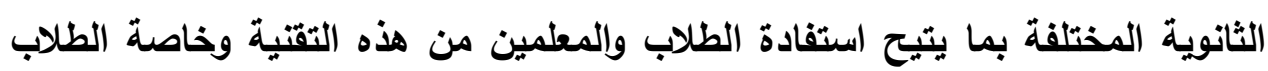

لكي يمارسوا الأنشطة اللاصفية.

r - تدريب المعلمين والطلاب على كيفية استخدام المعامل الافتراضية في عملية التدريس. ؛ - استفادة المسؤولين عن تطوير برامج الكمبيوتز التعليمي من هذه الدراسة، والدراسات

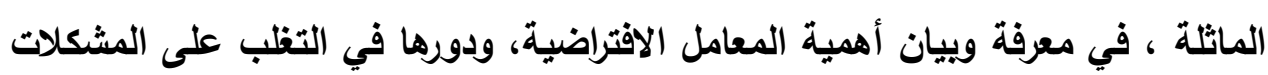

$$
\text { التي تواجه المعامل التقليدية. }
$$

ه - تدريب القائمين على تصميم برامج الكمبيوتز بالإدارة العامة لتقتيات التعليم بالأزهر

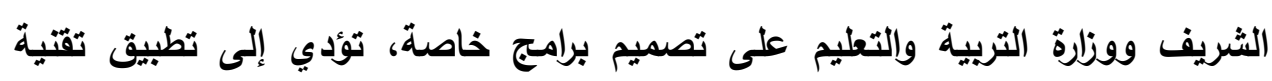
المعامل الافتراضية في تدريس العلوم بصفة عامة والفيزياء بصفة خاصة في المرحلة الثانوية.

צ - ضرورة استخدام الأساليب الحديثة في تدريس العلوم لزيادة الرغبة لدى الطلاب في حب الطب الاستطلاع العلمي، والكثف عن الطلاب المتميزين بحب الاستطلاع والعناية بهم لاستثمار قدراتهم العقلية بما يخدم مصالح الوطن.

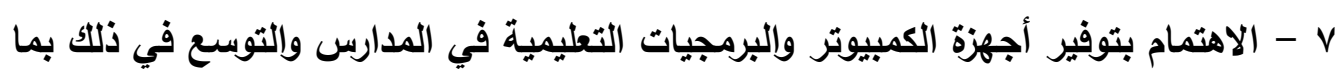
يتماشى مع الانفجار المعرفي والتقدم التكنولوجي الحالي.

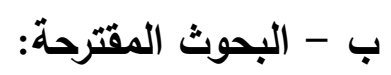

1 - فاعلية المعمل الافتراضي في تنمية التفكير العلمي لاى طلاب المرحلة الثانوية.

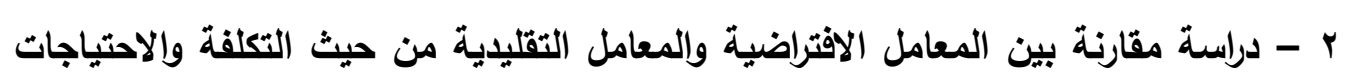

$$
\text { والعوائد والمخرجات في كلٍ منها. }
$$

ب - فاعلية المعمل الافتراضي في اكساب الطلاب مهارات التجارب المعملية في مقرر الفيزياء في المرحلة الثانوية.

؛ - - إجراء دراسات حول أثر استخدام المعل الافتراضي لدى بعض الفئات الخاصة، كالصم، المتفوقين أو المتأخرين دراسيًا . ه - دراسة حول اتجاهات معلمي العلوم في المرحلتين الإعدادية والثانوية نحو استخدام المعامل الافتراضية في تدريس العلوم. 
4 - دراسة حول فاعلية المعمل الافتراضي في تنمية التفكير الابتكاري والاستعداد الدائم للتعلم

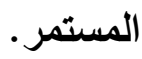

V - فاعلية المعمل الافتراضي في تدريس الفيزياء الكهريية على تنمية المهارات اليدوية في اجراء التجارب لاى طلاب الصف الثالث الثانوي. 
المراجع

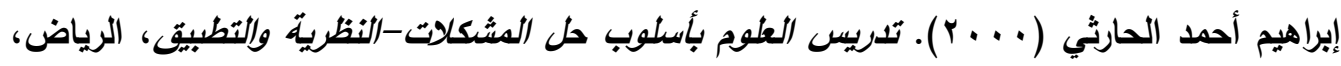

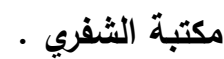

إبراهيم أحمد نوار(9 ج . ؟). تأثير التدريس بتكنولوجيا مختبر العلوم الافتراضي على تنمية مهارات التفكير العليا والوعي بتكنولوجيا المعلومات لاى طلاب الحلقة الثانية من مرحلة التعليم الأساسي، رسالة دكتوراه غير منشورة، كلية التربية جامعة كفر الشيخ.

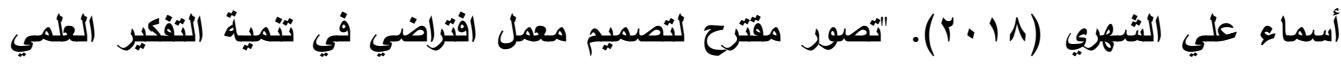

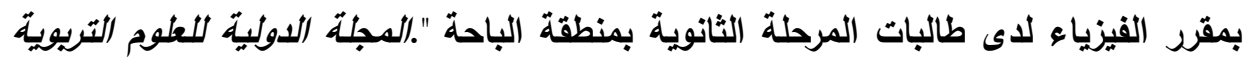

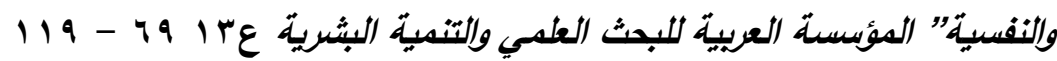

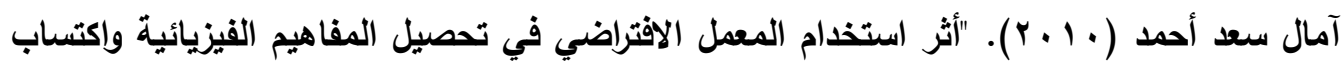
مهارات التفكير العليا والدافعية نحو تعلم العلوم لاى طالبات الصف الثالث الإعدادي ".(المجلة الثبلة

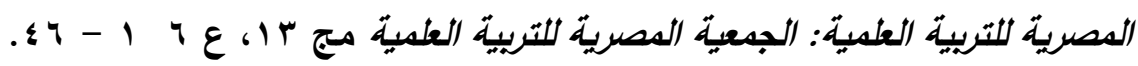

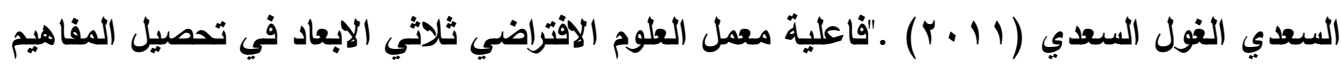

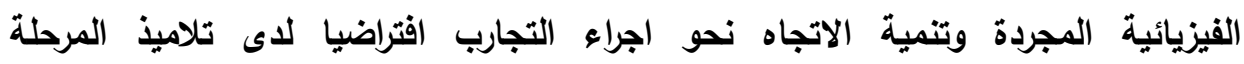

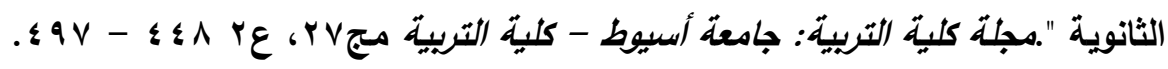

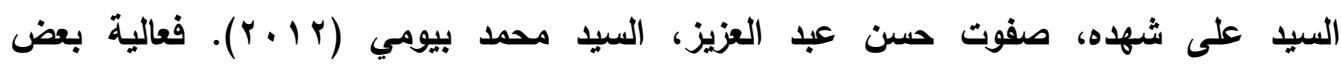

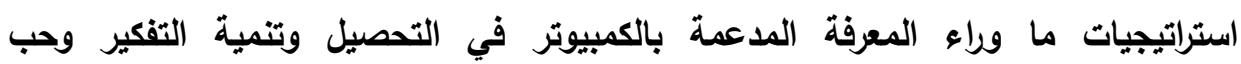

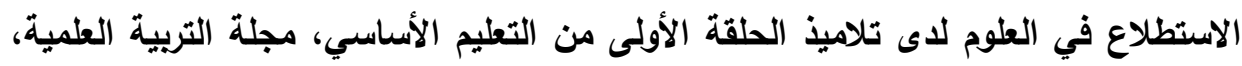

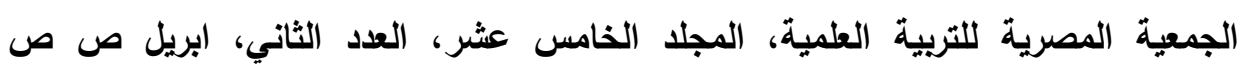
r $90: 1$.

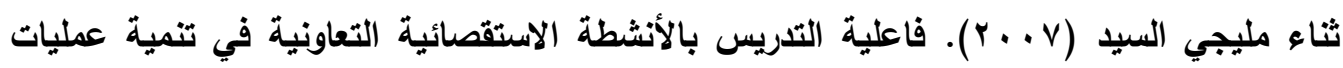

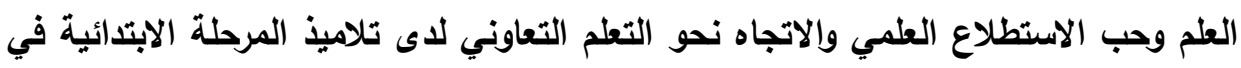

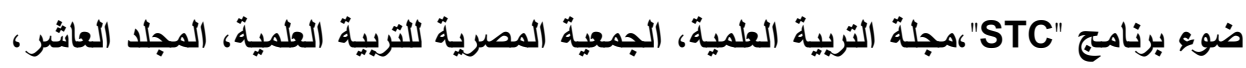

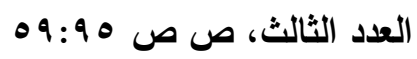
جبر محمد داود (سبتمبر 9 . . . ). معوقات استخد/م المعدل في تلايس العلوم من وجهة نظر معلمي

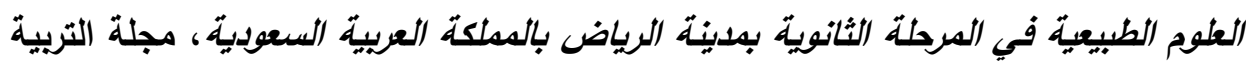

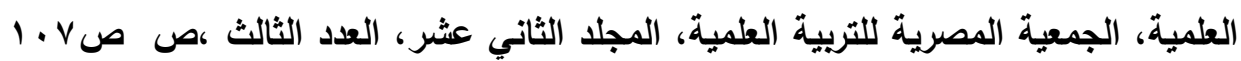




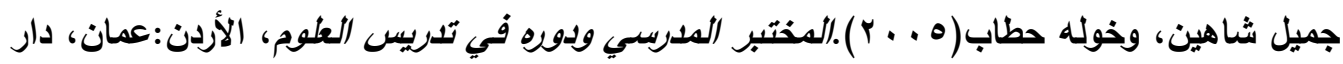
عالم الثقافة للنشر والتوزيع.

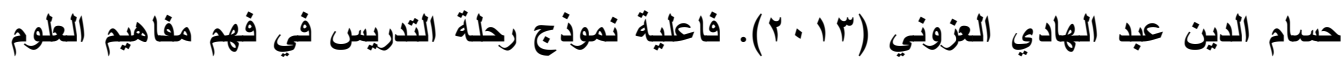
وتنمية بعض مهارات الاستقصاء وحب الاستطلاع العلمي لاى تلاميذ المرحلة الإعدادية،

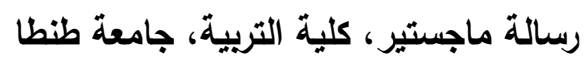

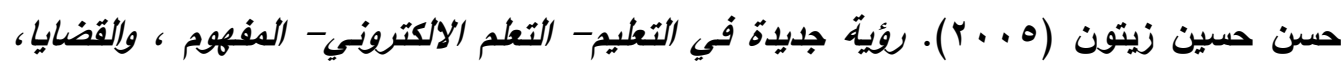
التطبيق، التقويث. عمان، الاردن: دار وائل للنشر.

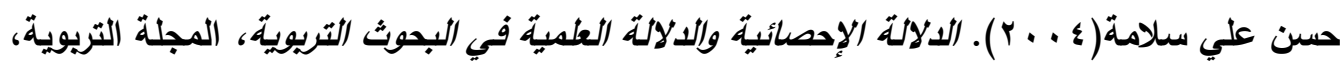

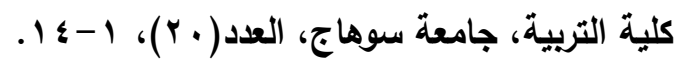

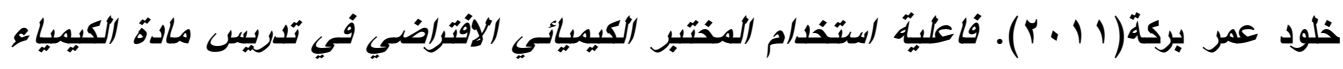

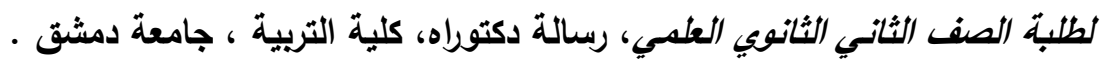

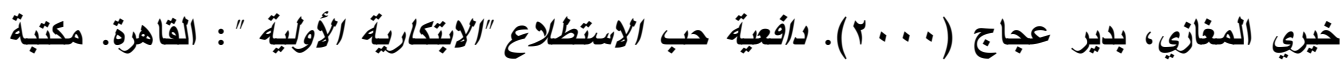
الأنجلو المصرية.

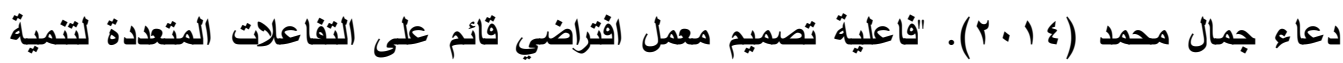
بعض مهارات التجارب المعلية في منهج الكيمياء لطلاب الصف الأول الثانوي ".مجلة كلية

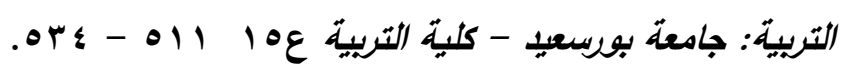

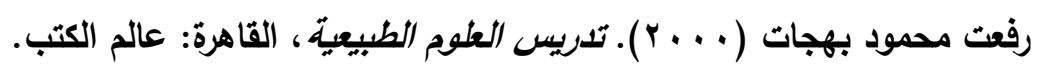

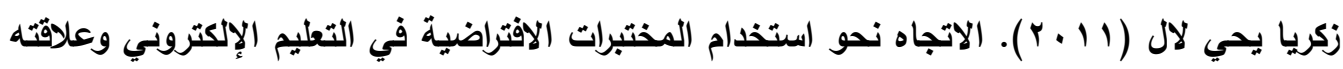
ببعض القدرات الإبداعية لدى عينه من طلاب وطالبات التعليم الثانوي في مدينة مكة المكرمة لإنة

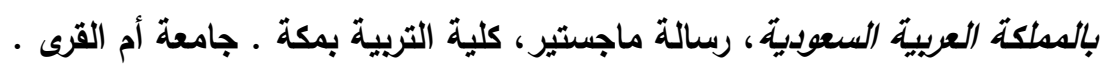

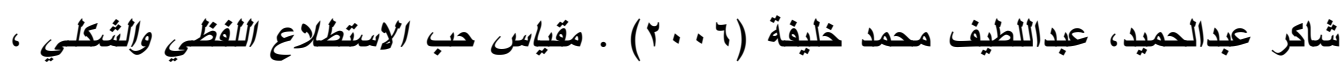
القاهرة، دار الغريب للطباعة والنشر والتوزيع. صلاح احمد مراد ( . . . . . الأساليب الإحصائية في العلوم النفسية والتريوية والاجتماعية ـ القاهرة: مكتبة الاتجلو المصرية.

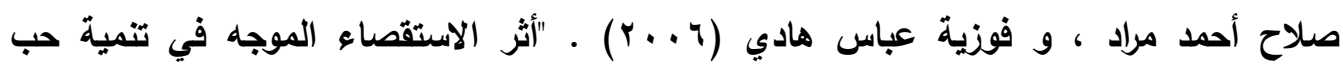

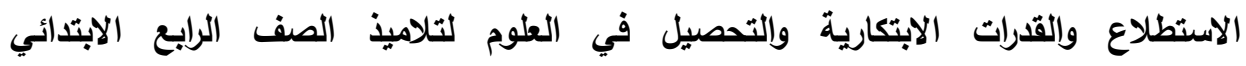

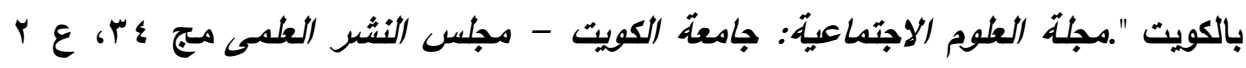


صلاح الاين محمود (ب99 1) ـ الأساليب الإحصائية والاستدلالية البلارا مترية و واللابارارترية في

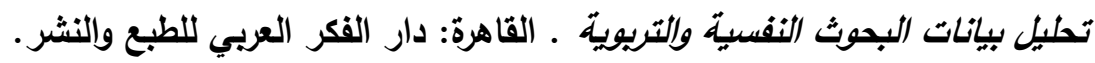

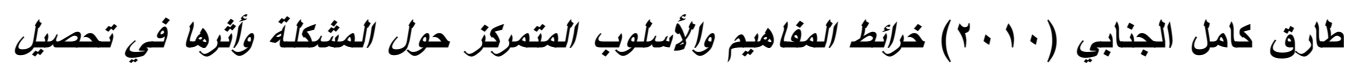

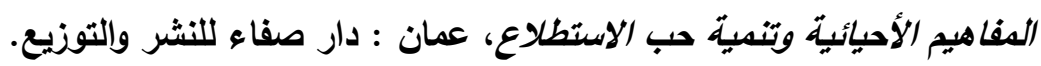

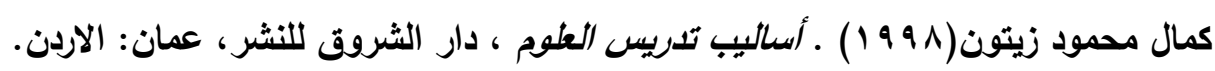

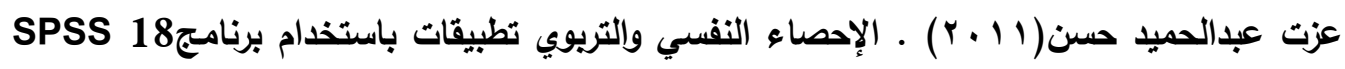
:القاهرة ، دار الفكر العربي للطباعة والنثر.

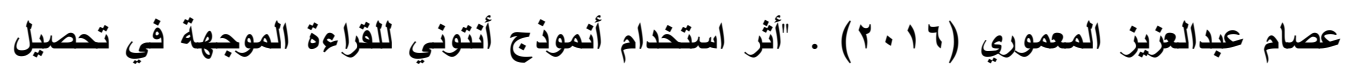

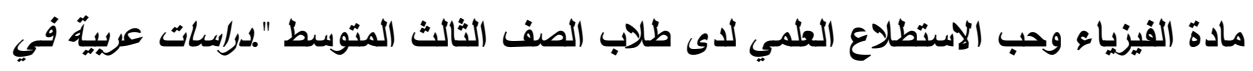

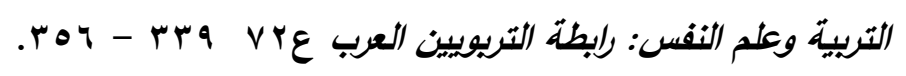

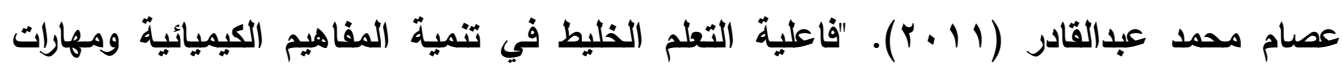

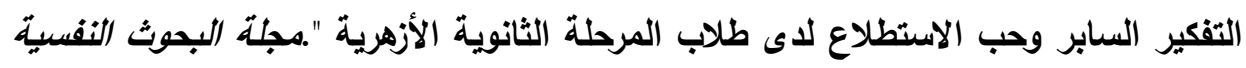

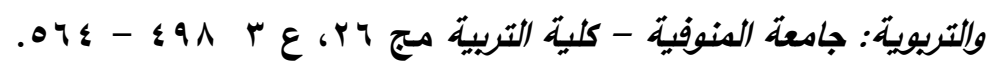

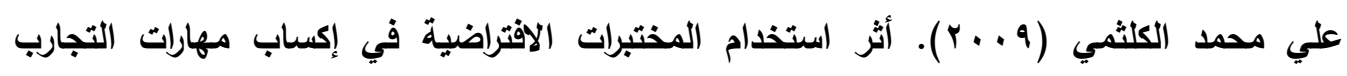

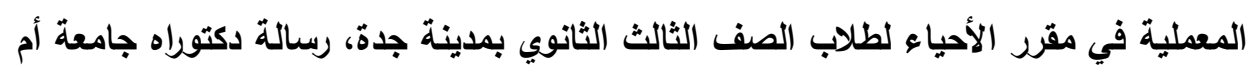
القرى.

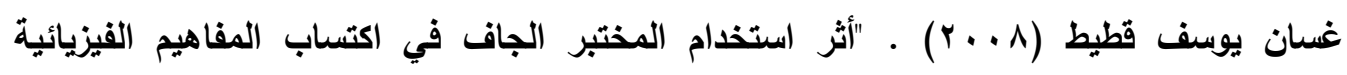

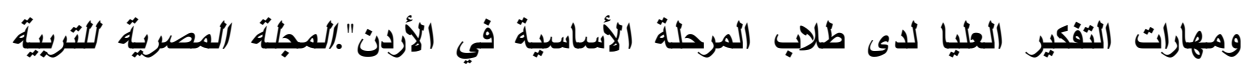

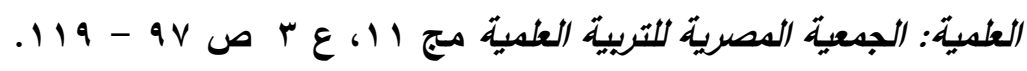

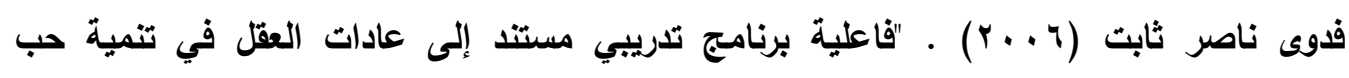

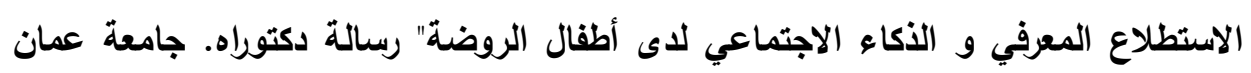

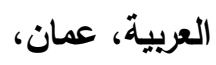
قسيم محمد الثناق، وحسن على أحمد دومي (9. . ب) أساسيات التعلم الإكتروني في العلوم . عمان : دار وائل للنشر.

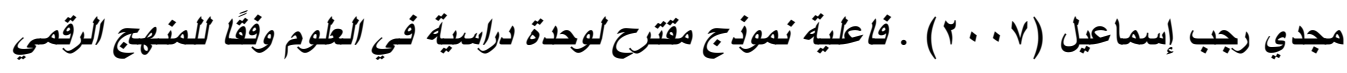

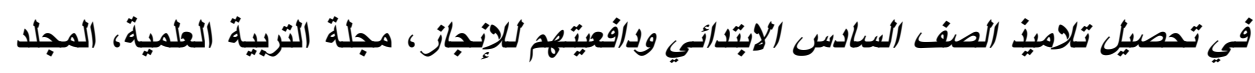
العاشر، العدد الثالث، ص ص ا:ب ؟ ك. 


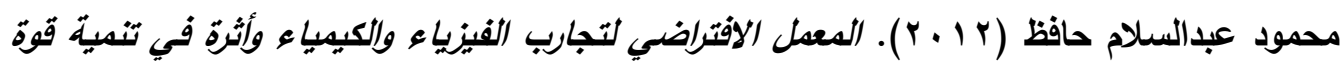

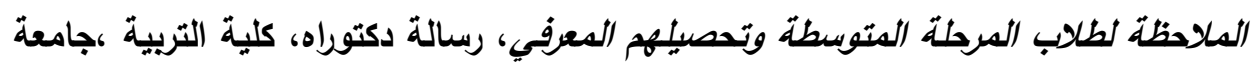

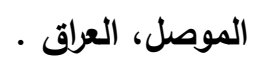

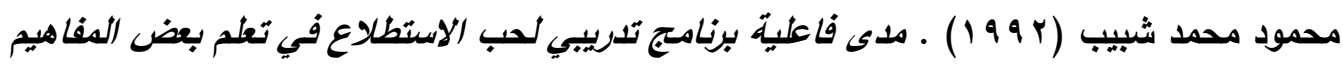

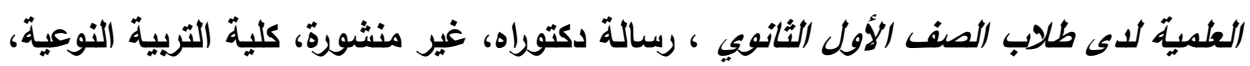
جامعة قنا. مجدي صلاح المهدي(1 . . r) ـ التعليم الافتراضي فلسفته- مقوماته - فرص تطبيقه . الاسكندرية: دار الجامعة الجديدة للطباعة وإلنشر.

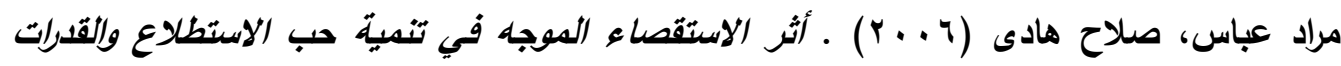

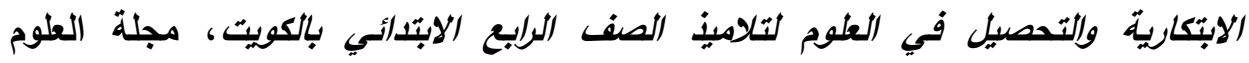

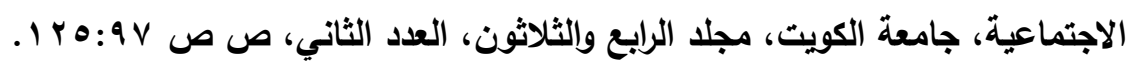

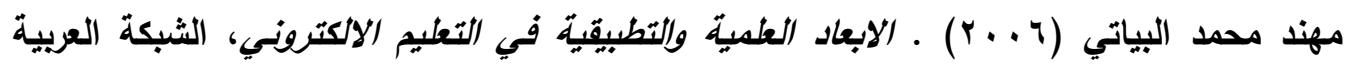

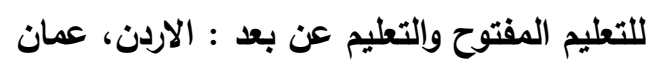

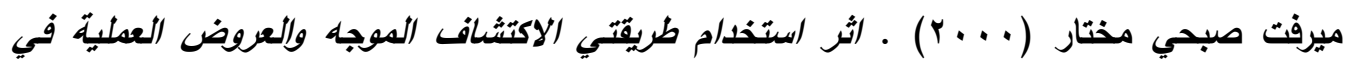

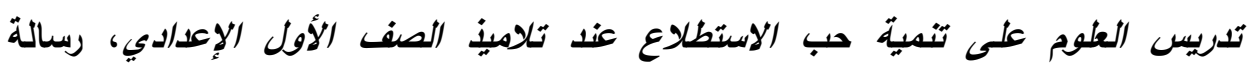

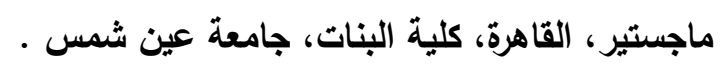

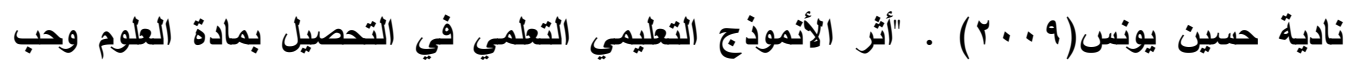
الاستطلاع العلمي لاى طالبات الصف الاول المتوسط ".مجلة القادسية في الآد/ب والثعلوم

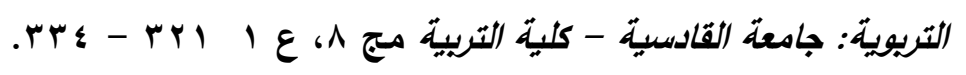

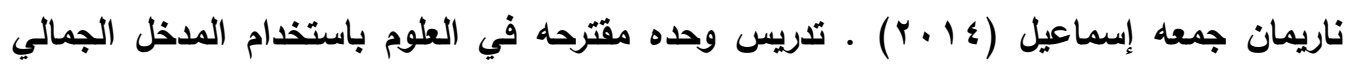
لتنمية حب الاستطلاع والتحصيل لاى تلاميذ المرحلة الإعدادية، رسالة دكتوراه، كلية التربية، ولئه جامعة الزقازيق.

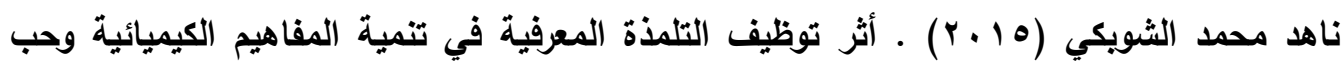

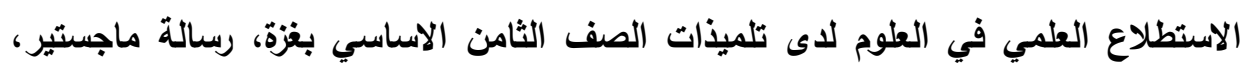
جامعة غزة الاسلامية.

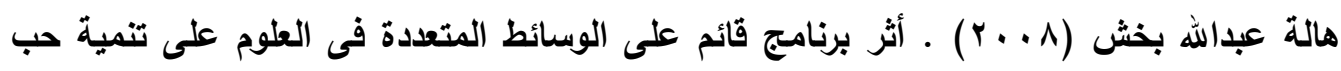

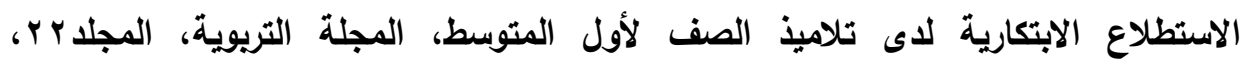

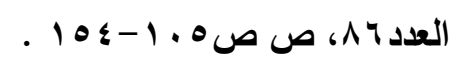




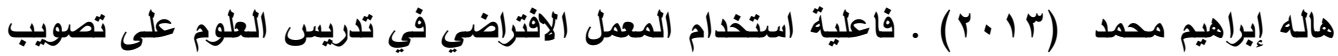
التصورات الخطأ لبعض المفاهيم العلمية وتنمية بعض عادات العقل لدى تلاميذ الصف الثاني

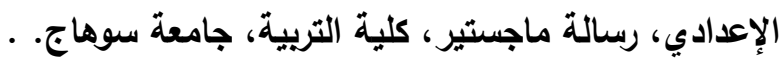

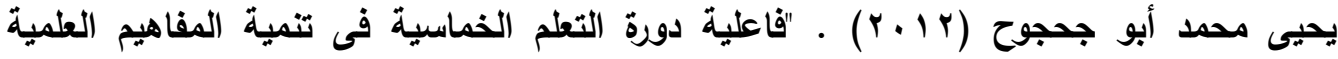

وعمليات العلم وحب الاستطلاع لاى تلاميذ الصف الثامن الأساسى بغزة فى مادة

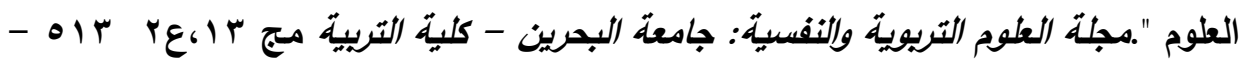
$.0 \leq \varepsilon$

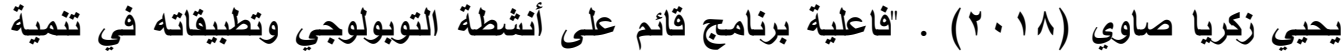
الحس الهندي وحب الاستطلاع للتوسع في دراسته لاى تلاميذ المرحلة الثانوية ".مجلة

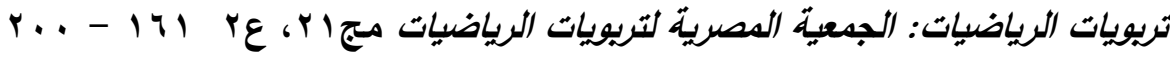

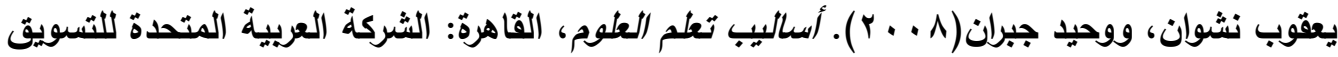
والتوريد.

Çalı!kan, S., Selçuk, G. S., \& Erol, M. (2012). Instruction of problem solving strategies: Effects on physics achievement and self-efficacy beliefs. Journal of Baltic Science Education, 9(1).

Campbell, T.et al.,(2010). Learning with web tools, simulations, and other technologies in science classroom. Journal of Science Education and Technology. V19,n5 . 505-511.

Cava's B. (2000):The use Computer Technology in seventh Gread Science Topics which contain Mathematics. Paper Presented at International special Education congress, University Manchester, UK

Duvall, R.,( 2001). Cultating Curiosity with comfort: Skills for inquiryBased Teaching .primary voices K-6, NI P. 33-36(ERIC);EJ630708.

Kim, H; Tepark , S; And others,(2001): Virtual Reality simulation in physics Education, Integrative Multimedia Electronic, journal of Computer Enhanced Learning, vol(3), No(2), October.

Koran, J. \& longino ,S (1980) "Curiosity and children's science learning" Science andchildren.20, pp 18-19.

Yaron, D.(2010), Karabiners, M., Lange, D., James G. Greene, \& Leichardt. G. (2010)."The Cheam Collective: Virtual labs and online activities for introductory chemistry courses, Science, Vol. 328, pp 59:78

Yemini ,Hao, Fang • (2009) :using Laboratory to improve physics Learning : simulation A case Exploratory Learning of Diffraction Gratian . first international workshop on Education Technology and Computer science . Wuhan, Hubei . IEEE pp.306-325 . 